\title{
POS HIPERTENSI SEBAGAI PENGENDALIAN DAN PENCEGAHAN HIPERTENSI
}

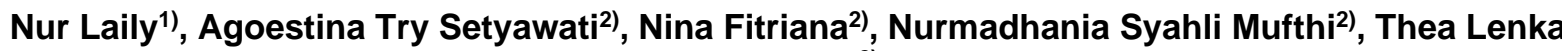 \\ Mannuela ${ }^{2)}$
1)Departemen Administrasi Kebijakan Kesehatan, Program Studi Kesehatan Masyarakat, Fakultas Kedokteran, Universitas Lammbung Mangkurat, Banjarmasin, Kalimantan Selatan, Indonesia Kalimantan Selatan, Indonesia \\ 2)Program Studi Kesehatan Masyarakat, Fakultas Kedokteran, Universitas Lammbung Mangkurat, Banjarmasin, \\ Corresponding author: Agoestina Try Setyawati \\ E-mail : agustinatrysetyawati@gmail.com
}

Diterima 24 Juni 2021, Direvisi 22 Juli 2021, Disetujui 22 Juli 2021

\begin{abstract}
ABSTRAK
Penyakit hipertensi merupakan masalah kesehatan yang penting untuk segera diatasi di Desa AluhAluh Besar RT. 03, Kecamatan Aluh-Aluh dikarenakan akibat jangka panjangnya dapat menimbulkan penyakit berbahaya seperti penyakit jantung dan stroke. Berdasarkan hasil diagnosa komunitas yang telah dilakukan pada 50 sampel Kepala Keluarga di Desa Aluh-Aluh Besar RT. 03 didapatkan sebanyak $23(11,8 \%)$ anggota rumah tangga yang terkena penyakit hipertensi. Kemudian, berdasarkan hasil survei kuesioner faktor risiko di Desa Aluh-Aluh Besar RT.03 diketahui masyarakat mempunyai kebiasaan mengonsumsi makanan tinggi garam, merokok, dan kurangnya aktivitas fisik sehingga mempengaruhi stabilitas tekanan darah. Media yang digunakan berupa booklet, video senam hipertensi, poster, dan powerpoint. Kegiatan PBL II yang dilakukan secara daring melalui aplikasi WhatsApp. Kegiatan intervensi dalam PBL II menghasilkan output bahwa terjadi peningkatan pengetahuan dan sikap pada masyarakat Desa Aluh-Aluh Besar RT. 03 mengenai penyakit hipertensi berdasarkan hasil pre-test dan post-test yang telah diisi masyarakat yaitu hasil rerata pre-test pengetahuan 68 lalu meningkat pada post-test menjadi 94,7 . Sedangkan hasil rerata pre-test sikap yaitu 65,3 lalu meningkat pada post-test menjadi 96.
\end{abstract}

Kata kunci: hipertensi; penyuluhan; PBL II; desa aluh-aluh besar RT. 03

\begin{abstract}
Hypertension disease is an important health problem to be addressed immediately in Aluh-Aluh Besar Village RT. 03, Aluh-Aluh subdistrict because of its long-term consequences can cause dangerous diseases such as heart disease and stroke. Based on the results of community diagnoses that have been done on 50 samples of family heads in Aluh-Aluh Besar Village RT. 03 obtained as many as 23 $(11.8 \%)$ household members affected by hypertension. Then, based on the results of the survey questionnaire risk factors in the village of Aluh-Aluh Besar RT.03 known people have a habit of consuming foods high in salt, smoking, and lack of physical activity so as to affect the stability of blood pressure. Media used in the form of booklets, videos of hypertension gymnastics, posters, and powerpoints. PBL II activities conducted online through WhatsApp application. Intervention activities in PBL II resulted in the output that there was an increase in knowledge and attitude in the community of Aluh-Aluh Besar Village RT. 03 about hypertensive disease based on the results of pre-test and posttest that has been filled by the community, namely the average results of pre-test knowledge 68 then increased in post-test to 94.7 . While the average pre-test attitude is 65.3 and then increased in the posttest to 96 .
\end{abstract}

Keywords: hypertension; counseling; PBL II; aluh-aluh besar village RT. 03

\section{PENDAHULUAN}

Hipertensi menurut Word Health Organization (WHO) merupakan penyakit yang menimbulkan kesakitan dan kematian di seluruh dunia. Hipertensi juga diartikan sebagai peningkatan tekanan sistol mencapai 140 $\mathrm{mmHg}$ sampai lebih dan peningkatan diastolik $90 \mathrm{mmHg}$ lebih, diukur dengan keadaan tenang dan cukup. Diagnosis hipertensi tidak berdasarkan pada peningkatan tekanan darah yang hanya sekali. Hipertensi disebut juga sebagai the sillent killer karena sering tidak menunjukkan gelaja apapun selama sepuluh sampai dua puluh tahun dan biasanya baru diketahui apabila telah terjadi komplikasi pada organ target seperti jantung, ginjal, otak, dan 
mata sehingga pengobatannya terlambat dan mengurangi harapan hidup karena kelemahan fungsi organ-organ tersebut yang berakibat kecacatan bahkan kematian.Tekanan darah harus diukur dalam posisi duduk dan berbaring. Ada dua macam hipertensi yaitu, hipertensi esensial atau primer dan hipertensi sekunder. Sembilan puluh persen dari semua kasus hipertensi adalah primer. Tidak ada penyebab yang jelas tentang hipertensi esensial (primer), sekalipun ada beberapa teori yang menunjukkan adanya faktor-faktor genetik, perubahan hormon, dan perubahan simpatis. Hipertensi sekunder adalah akibat dari penyakit atau gangguan tertentu (Oktaviarini et al., 2019). Berdasarkan data Riset Kesehatan Dasar tahun 2018, prevalensi hipertensi berdasarkan hasil pengukuran pada penduduk umur $\geq 18$ tahun di Kalimantan Selatan dengan peringkat nomor 1 di Indonesia. Tingginya kasus hipertensi ini disebabkan perilaku gaya hidup dan pola makan yang tidak seimbang. Kejadian hipertensi di Indonesia mencapai angka $34,1 \%$ dan lebih banyak terjadi pada wanita dengan angka 36,9\%. Berdasarkan data Dinas Kesehatan Kabupaten Banjar tahun 2017, penderita penyakit Hipertensi di wilayah kerja puskesmas yang ada di Kabupaten Banjar menempati urutan ke-15 dari 24 puskesmas yang ada di Kabupaten Banjar dengan prevalensi $17,86 \%$ penderita hipertensi. Kota Banjarmasin merupakan kota tertinggi dengan penderita hipertensi yaitu mencapai $100 \%$ yang artinya bahwa orang yang dilakukan pengukuran tekanan darah tinggi di Kabupaten/Kota tersebut terdeteksi semua terkena hipertensi (Aryzki et al., 2018). Berdasarkan hasil diagnosa komunitas yang telah dilakukan pada 50 sampel Kepala Keluarga di Desa Aluh-Aluh Besar RT. 03 didapatkan sebanyak 23 (11,8\%) anggota rumah tangga yang terkena penyakit hipertensi. Berdasarkan hasil dari kuesioner faktor risiko yang didapatkan dari 34 sampel menunjukkan bahwa ada beberapa faktor yang menyebabkan masyarakat di Desa Aluh-Aluh Besar RT. 03 menderita hipertensi diantaranya yaitu diperparah oleh kebiasaan masyarakat yang menyukai makanan asin selain disebabkan oleh faktor usia, kemudian merokok dan kurangnya aktivitas fisik seperti berolahraga, kurangnya konsumsi buah dan sayur, serta kurangnya memeriksakan tekanan darah secara rutin di pelayanan kesehatan. Kemudian, berdasarkan hasil survei kuesioner faktor risiko di Desa Aluh-Aluh Besar RT.03 diketahui masyarakat mempunyai kebiasaan mengonsumsi makanan tinggi garam, merokok, dan kurangnya aktivitas fisik sehingga mempengaruhi stabilitas tekanan darah (Bety Semara Lakhsmi, 2021).

Oleh sebab itu, perlu dilakukan kegiatan pemberdayaan masyarakat di Desa Aluh-Aluh Besar RT. 03, yang bertujuan untuk meningkatkan pengetahuan dan sikap masyarakat dalam pencegehan dan pengendalian hipertensi. Kegiatan yang dilakukan adalah pelaksanaan pos hipertensi secara daring dengan salah satu kegiatan dilakukan melalui penyuluhan terkait pengendalian dan pencegahan penyakit hipertensi agar dapat menekan angka kematian yang disebebkan oleh tekanan darah tinggi (Dede Rina, Nita Fitria, 2021). Kegiatan penyuluhan ini juga bertujuan agar masyarakat dapat merubah pola konsumsi makanan dan menerapkan perilaku hidup sehat dalam melaksanakan aktivitas sehari-hari.

\section{METODE}

Pos hipertensi dilaksanakan secara daring melalui grup WhatsApp pada 16 November - 1 Desember 2020 dengan metode penyuluhan. Peserta dalam kegiatan ini sebanyak 15 orang anggota masyarakat yang berada di Aluh-Aluh Besar RT. 03. Kegiatan pos hipertensi diawali dengan seluruh partisipan mengisi soal pre-test terkait pengendalian dan pencegahan hipertensi menggunakan Platform Google Form yang telah disiapkan oleh kelompok. Kemudian kelompok membagikan materi terkait informasi terkait pengendalian dan pencegahan hipertensi melalui media booklet, video senam hipertensi, poster, dan powerpoint serta diberikan penjelasan lebih rinci dari masing-masing anggota kelompok. Setelah itu, seluruh masyarakat diberi kesempatan untuk bertanya dan berdiskusi mengenai isi media yang diberikan. Akhir dari kegiatan adalah seluruh masyarakat diminta untuk mengisi soal post-test kembali. Soal pretest dan post-test terbagi menjadi 2 bagian, yaitu pertanyaan tentang pengetahuan dan pertanyaan tentang sikap dalam pengendalian dan pencegahan hipertensi.

Instrumen yang digunakan adalah kuesioner pre-test dan post-tes yang berisi pertanyaan-pertanyaan yang berkaitan dengan pengendalian dan pencegahan hipertensi, kepada masyarakat Aluh-Aluh Besar RT. 03 melalui Platform Google Form, kemudian media yang digunakan berupa booklet, video senam hipertensi, poster, dan powerpoint. Data yang diperoleh dari hasil kuesioner diolah dalam bentuk tabel dan dibandingkan dengan nilai standar pada masing-masing item untuk kemudian diambil kesimpulan secara obyektif. 
Adapun langkah yang telah ditempuh pada kegian Pengalaman Belajar Lapangan (PBL) II yaitu:

\section{Tahap Perencanaan dan Persiapan}

Pada tahap ini, dalam perencanaan dan persiapan kegiatan Pengalaman Belajar Lapangan (PBL) II yang dilakukan oleh kelompok 21 RT. 03 di Desa Aluh-Aluh Besar dilakukan secara daring antara lain:

1. Mengumpulkan Kontak Masyarakat

Sebelum dilakukannya kegiatan Praktik

Belajar Lapangan (PBL) II ini, terlebih dari dari tim UP PBL beserta mahasiswa melakukan pengumpulan kontak masyarakat yang dijadikan sasaran dalam kegiatan intervensi. Kontak yang dikumpulkan disini adalah kontak yang terdaftar dalam WhatsApp karena kegiatan dilaksanakan via grup WhatsApp. Ketentuan jumlah minimal kontak masyarakat yang dimiliki sebanyak 15 kontak. Kelompok 21 sendiri sudah mendapatkan syarat kontak minimal, kontak masyarakat Desa Aluh-Aluh Besar RT. 03 yang dapat dikumpulkan sebanyak 15 kontak.

\section{Membuat Grup WhatsApp}

Setelah dilakukan proses pengumpulan kontak masyarakat Desa Aluh-Aluh Besar RT. 03, dilanjutkan dengan pembuatan grup WhatsApp dengan nama "Aluh-Aluh Besar RT. 03" yang didalamnya terdapat 15 warga AluhAluh Besar RT. 03, 4 orang tim kelompok PBL serta dosen pembimbing dari kelompok 21.

3. Rapat Persiapan Kegiatan

Setelah mempunyai grup WhatsApp, kelompok melakukan rapat persiapan yang membahas terkait rangkaian kegiatan, metode kegiatan, dan media kegiatan yang akan dilakukan pada kegiatan intervensi Praktik Belajar Lapangan (PBL) II ini. Rapat persiapan dilakukan via online melalui grup WhatsApp kelompok 21.

4. Menyusunan Pre-test dan Post-test, Materi, dan Media yang digunakan dalam Intervensi,

Setelah kelompok melakukan rapat persiapan, dilanjutkan dengan penyusunan dan pembuatan pre-post, materi, dan media yang digunakan dalam kegiatan intervensi Praktik Belajar Lapangan (PBL) 2 ini. Pre-post test, kelompok 21 membuat soal pilihan ganda sebanyak 10 soal yang terbagi menjadi 5 soal tentang pengetahuan hipertensi, 5 soal tentang sikap hipertensi. Soal-soal pre-post dibuat berdasarkan materi yang akan disampaikan, yaitu terkait dengan pengendalian dan pencegahan hipertensi.

5. Konsultasi Pre-test dan Pos-test

Soal pre-test dan post-test, materi, dan media yang akan digunakan dalam kegiatan intervensi yang sudah dibuat serta disusun selanjutnya dikonsultasikan kepada dosen pembimbing dan menunggu persetujuan.

6. Penyusunan Jadwal Kegiatan

Persiapan terakhir yang dilakukan adalah penyusunan jadwal kegiatan intervensi Praktik Belajar Lapangan (PBL) II secara internal kelompok. Walaupun sudah ada timeline yang telah diberikan oleh tim UP PBL, penyusunan jadwal kegiatan ini diharapkan dapat memperlancar jalannya kegiatan.

\section{Tahap Pelaksanaan dan Proses}

Pada tahap ini, dalam pelaksanaan dan proses kegiatan Pengalaman Belajar Lapangan (PBL) II yang dilakukan oleh kelompok $21 \mathrm{RT}$. 03 di Desa Aluh-Aluh Besar melakukan kegiatan berupa penyuluhan terkait penyakit hipertensi kepada dengan jumlah peserta sebanyak 15 orang. Kegiatan dilaksanakan melalui Grup WhatsApp Desa Aluh-Aluh Besar RT. 03, yang dihadiri oleh ketua RT, pembimbing, dan warga RT. 03. Kegiatan hari pertama dilakukan pembagian soal pretest kepada peserta untuk mengetahui seberapa besar pengetahuan peserta tentang materi yang akan disampaikan oleh penyuluh. Setelah seluruh peserta selesai menjawab soal pre-test tersebut, di hari kedua dilanjutkan dengan inti acara yaitu pemberian materi terkait penyakit hipertensi.

Materi yang dibagikan berupa booklet, poster, video, dan powerpoint mengenai penyakit hipertensi di Grup WhatsApp Desa Aluh-Aluh Besar RT.03 yang pemberian materinya diberikan oleh Mahasiswa Kesehatan Masyarakat dari tim kelompok 21 PBL agar warga dapat membaca dan memahami materi yang telah disampaikan. Setelah dilakukan pemberian media edukasi, penyuluh akan mempersilahkan peserta untuk bertanya mengenai isi dari media yang sudah berikan. Tujuannya agar peserta yang kurang paham dengan materi yang diberikan dapat bertanya, sehingga penyuluh dapat menjelaskan poin-poin yang belum dipahami oleh peserta dari materi tersebut. Para peserta menerima edukasi yang diberikan melalui media booklet, video senam hipertensi, poster, dan powerpoint yang telah dibagikan, dengan melihat dari reaksi peserta yang aktif dengan bertanya. Setelah pemberian materi selesai dibagikan soal post-test terkait materi yang telah disampaikan oleh penyuluh.

Sehari setelah itu, hal selanjutnya yang dilakukan adalah cross check data, perekapan data, analisis data dan penyusunan laporan kegiatan PBL.

Tahap Monitoring dan Evaluasi 
Pada tahap ini, dalam monitoring dan evaluasi kegiatan Pengalaman Belajar Lapangan (PBL) II yang dilakukan oleh kelompok 21 RT. 03 di Desa Aluh-Aluh Besar dilakukan pada saat kegiatan penyuluhan berlangsung dan setelah kegiatan penyuluhan selesai dengan cara melakukan pemantauan dan pengawasan terhadap proses, hasil dan dampak dari kegiatan penyuluhan ini. Kegiatan edukasi ini diharapkan dapat meningkatkan pengetahuan, sikap dan bisa merubah perilaku masyarakat tentang pola hidup sehat dan pencegahan penyakit hipertensi. Adapun, pelaksanaan kegiatan dan evaluasi kegiatan yang dilakukan yaitu

1. Pelaksanaan Kegiatan Intervensi PBL

II

Kegiatan intervensi berupa penyuluhan melalui grup WhatsApp kami pada tanggal 16 November - 1 Desember 2020. Sebelum melakukan kegiatan intervensi kami memastikan media intervensi sudah siap dan telah dikonsulkan kepada dosen pembimbing, selain itu pemilihan waktu kami sesuaikan dengan kegiatan warga, kami memgambil waktu pukul 15.00 WITA. Tanggal 16 November 2020 kami melakukan penyuluhan di grup dengan materi terkait pengendalian dan pencegahan hipertensi.

Kegiatan penyuluhan yang kami lakukan dimulai dari pembukaan, pengisian pre-test, pemberian materi dan dilanjut dengan post-test dan penutup. Pengisian pre-post test menggunakan Platform Google Form, kami memberikan link kepada masyarakat agar dapat memudahkan pengisian pre-post test, kami juga memnatau dan meberikan waktu agar warga bisa mengisi pre-test terlebih dahulu sebelum kami memberikan materi. Media intervensi berupa materi mengenai pengendalian dan pencegahan hipertensi melalui booklet, video senam hipertensi, poster, dan powerpoint.

2. $\begin{aligned} & \text { Evaluasi terhadap Pelaksanaan } \\ & \text { Intervensi }\end{aligned}$

Berdasarkan kegiatan intervensi yang kami lakukan di Desa Aluh-Aluh Besar RT. 03, maka evaluasi pelaksanaan kegiatan adalah sebagai berikut:

\section{a. Evaluasi Input}

Input dalam pelaksanaan kegiatan intervensi ini adalah sebagai berikut:

1) Tersedianya sarana dan prasarana dalam pelaksanaan kegiatan intervensi. Sarana yang digunakan dalam pembuatan materi yaitu komputer atau laptop untuk menyipakan materi sedangkan prasarana yang kami gunkan untuk penyuluhan adalah aplikasi WhatsApp. Tersedianya infromasi yang akurat dan terpercaya untuk masyarakat, yang didukung oleh Mahasiswa dari Program Studi Kesehatan Masyarakat dalam memberikan materi pada kegiatan penyuluhan.

3) Adanya partisipasi masyarakat yang b. $\quad$ ada didalam grup

Evaluasi jangka pendek dilakukan dari kegiatan intervensi adalah dengan pemberian kuesioner melalui pre dan post test. Kegiatan intervensi yang dilakukan tidak lepas dari beberapa kendala, yaitu diperlukan waktu yang cukup lama dalam pengisian kuesioner oleh warga Desa Aluh-Aluh Besar RT. 03 dikarenakan beberapa peserta sedang sibuk sehingga terlambat untuk merespon pesan dari beberapa mahasiswa tetapi hambatan tesrsebut dapat diatasi oleh mahasiswa.

c. Evaluasi Output

Evaluasi terhadap output (summative evaluation, impact evaluation) dilaksanakan setelah pekerjaan selesai dilaksanakan untuk mengetahui output, efek atau dampak program apakah sudah sesuai dengan target yang ditetapkan sebelumnya. Output dari kegiatan intervensi penyuluhan yang dilakukan adalah meningkatnya pengetahuan untuk menangani permasalahan lingkungan khususnya permasalahan yang terkait dengan hipertensi.

\section{HASIL DAN PEMBAHASAN}

Terdapat sebanyak 15 orang masyarakat Desa Aluh-Aluh Besar RT. 03 yang berpartisipasi pada kegiatan Pengalaman Belajar Lapangan (PBL) II, karakeristik responden dapat dilihat pada tabel 1. berikut ini.

Tabel 1. Karakeristik Responden

\begin{tabular}{|c|c|c|c|}
\hline No & Karakteristik & Jumlah & $\begin{array}{l}\text { Persentase } \\
\text { (\%) }\end{array}$ \\
\hline & Usia & & \\
\hline 1. & $\begin{array}{l}\text { Remaja Akhir } \\
(17-25 \text { tahun) }\end{array}$ & 8 & 53,3 \\
\hline 2. & $\begin{array}{l}\text { Dewasa Awal } \\
\text { (26 - } 35 \text { tahun) }\end{array}$ & 4 & 26,7 \\
\hline 3. & $\begin{array}{l}\text { Dewasa Akhir } \\
\text { (36- } 45 \text { tahun) }\end{array}$ & 2 & 13,3 \\
\hline 4. & $\begin{array}{l}\text { Manula } \\
\text { (>65 tahun) } \\
\text { Jenis Kelamin }\end{array}$ & 1 & 6,7 \\
\hline 1. & Laki - laki & 6 & 40 \\
\hline 2. & $\begin{array}{l}\text { Perempuan } \\
\text { Pekerjaan }\end{array}$ & 9 & 60 \\
\hline 1. & Pedagang & 3 & 20 \\
\hline 2. & Petani & 1 & 6,7 \\
\hline
\end{tabular}

Tabel 1. Karakeristik Responden 


\begin{tabular}{|c|c|c|c|c|c|c|c|c|c|}
\hline No & Karakteristik & Jumlah & $\begin{array}{l}\text { Persentase } \\
(\%)\end{array}$ & $\begin{array}{l}\text { Tabel } \\
\text { Pengen }\end{array}$ & $\begin{array}{l}3 . \\
\text { dalian }\end{array}$ & ikap & $\begin{array}{r}\text { Resp } \\
\text { ncegal }\end{array}$ & $\begin{array}{l}\text { nden } \\
\text { an Hipe }\end{array}$ & $\begin{array}{l}\text { Mengenai } \\
\text { ertensi }\end{array}$ \\
\hline \multirow{3}{*}{$\begin{array}{l}3 . \\
4 .\end{array}$} & \multirow{4}{*}{$\begin{array}{l}\text { Pegawai Swasta } \\
\text { Tidak Bekerja (lbu } \\
\text { Rumah Tangga) } \\
\text { Pendidikan }\end{array}$} & \multirow{3}{*}{$\begin{array}{l}3 \\
8\end{array}$} & \multirow{3}{*}{$\begin{array}{l}20 \\
53,3\end{array}$} & \multirow[t]{2}{*}{ Sikap } & \multicolumn{2}{|c|}{ Pre-test } & \multicolumn{2}{|c|}{ Post-test } & \multirow{2}{*}{$\begin{array}{r}\text { Hasil Uji } \\
\text { Wilcoxon }\end{array}$} \\
\hline & & & & & $f(x)$ & $(\%)$ & $f(x)$ & (\%) & \\
\hline & & & & Positif & 11 & 73 & 15 & 100 & \multirow{3}{*}{$P=0.059$} \\
\hline \multirow{3}{*}{$\begin{array}{l}1 . \\
2 .\end{array}$} & & 3 & & Negatif & 4 & 27 & 0 & 0 & \\
\hline & \multirow{2}{*}{$\begin{array}{l}\text { Tinggi (D3/S1) } \\
\text { Menengah } \\
\text { (SMA/SMK) }\end{array}$} & & \multirow{2}{*}{$\begin{array}{l}20 \\
33,3\end{array}$} & Total & 15 & 100 & 15 & 100 & \\
\hline & & & & \multirow{3}{*}{\multicolumn{6}{|c|}{$\begin{array}{l}\text { Berdasarkan tabel 3. sikap responden } \\
\text { enai pengendalian dan pencegahan } \\
\text { ensi didapatkan Hasil uji wilcoxon sikap } \\
\text { enai pengendalian dan pencegahan }\end{array}$}} \\
\hline \multirow[t]{2}{*}{3.} & $\begin{array}{l}\text { Rendah } \\
\text { SMP/MTs) }\end{array}$ & 7 & 46,7 & & & & & & \\
\hline & Total & 15 orang & 100 & & & & & & \\
\hline $\begin{array}{l}\text { terda } \\
\text { Peng } \\
\text { berd } \\
\text { maka }\end{array}$ & $\begin{array}{l}\text { Berdasarkan karak } \\
\text { at } 15 \text { orang m } \\
\text { laman Belajar Lapar } \\
\text { sarkan hasil penelitia } \\
\text { diketahui tingk } \\
\text { rakat Desa Aluh-A }\end{array}$ & $\begin{array}{l}\text { eristik res } \\
\text { ngikuti k } \\
\text { gan (PBL) }\end{array}$ & $\begin{array}{l}\text { nden } \\
\text { yiatan } \\
\text { dan } \\
\text { ukan, } \\
\text { huan }\end{array}$ & $\begin{array}{l}\text { miperten } \\
0.059< \\
\text { mean a } \\
\text { terdapat } \\
\text { pencega } \\
\text { sesudar }\end{array}$ & $\begin{array}{l}\text { ISI dic } \\
0.05 \\
\text { ntara } \\
\text { t pe } \\
\text { ahan } \\
\text { o pem }\end{array}$ & $\begin{array}{l}\text { patka } \\
\text { ang a } \\
\text { ilai pr } \\
\text { edaal }\end{array}$ & $\begin{array}{l}n \text { nilal } \\
\text { tinya t } \\
\text { e-test } \\
\text { t ting } \\
\text { nsi an } \\
\text { nateri. }\end{array}$ & $\begin{array}{l}\text { ull yal } \\
\text { rdapat } \\
\text { an pos } \\
\text { at si } \\
\text { rra se }\end{array}$ & $\begin{array}{l}\text { perbedaan } \\
\text { t-test, yaitu } \\
\text { kap pada } \\
\text { oelum dan }\end{array}$ \\
\hline
\end{tabular}

masyarakat Desa Aluh-Aluh Besar RT.03 mengenai pengendalian dan pencegahan hipertensi yang dapat dilihat pada tabel. 2 berikut ini.

Tabel 2. Pengetahuan Responden Mengenai Pengendalian dan Pencegahan Hipertensi

\begin{tabular}{lccccc}
\hline Pengetahuan & Pre-test & Post-test & $\begin{array}{c}\text { Hasil Uji } \\
\text { Wilcoxon }\end{array}$ \\
\hline Tinggi & $\mathrm{f}(\mathrm{x})$ & $(\%)$ & $\mathrm{f}(\mathrm{x})$ & $(\%)$ & \\
\hline Rendah & 12 & 80 & 15 & 100 & $P=0.034$ \\
\hline Total & 3 & 20 & 0 & 0 & \\
\hline
\end{tabular}

Berdasarkan tabel 2. pengetahuan

responden mengenai pengendalian dan pencegahan hipertensi didapatkan hasil uji Wilcoxon terhadap hasil pre-test dan post-test pengetahuan mengenai pengendalian dan pencegahan hipertensi menunjukkan $p$ value $0.034<0.05$ yang artinya terdapat perbedaan mean antara nilai pre-test dan post-test, yaitu terdapat perbedaan tingkat pengetahuan pada pengendalian dan pencegahan hipertensi antara sebelum dan sesudah pemberian materi.

Pengetahuan merupakan hasil tahu dan ini terjadi setelah orang melakukan penginderaan terhadap suatu objek tertentu. Penginderaan terjadi melalui panca indera manusia, yakni indera penglihatan, pendengaran, penciuman, rasa dan raba. Sebagian besar pengetahuan manusia diperoleh melalui mata dan telinga (Wibowo, 2018). Pengetahuan atau kognitif merupakan dominan yang sangat penting untuk terbentuknya tindakan seseorang atau overt behavior, karena dari pengalaman dan penelitian ternyata perilaku yang didasari oleh pengetahuan akan lebih langgeng dari pada perilaku yang tidak didasari oleh pengetahuan (Hendrawan, 2019). Berdasarkan hasil penelitian yang dilakukan, maka diketahui sikap masyarakat Desa Aluh-Aluh Besar RT.03 mengenai pengendalian dan pencegahan hipertensi yang dapat dilihat pada tabel. 3 berikut ini.

Sikap tumbuh diawali dari pengetahuan yang dipersepsikan sebagai sesuatu hal yang baik atau positif maupun tidak baik atau negatif, kemudian diinternalisasikan kedalam dirinya. $\mathrm{Hal}$ yang diketahui akan mempengaruhi perilaku. Jika yang dipersepsikan tersebut bersifat positif, maka seseorang cenderung berperilaku sesuai dengan persepsinya sebab ia merasa setuju dengan yang diketahuinya. Namun sebaliknya, jika ia mempersepsikan secara negatif, maka ia pun cenderung menghindari atau tidak melakukan apa yang dipersepsikan ke dalam perilakunya. Dengan kata lain, seseorang yang memiliki sikap positif akan menunjukkan perilaku yang positif pula (Desi Aianti, 2018).

Peningkat hasil rerata pengetahuan dan sikap pada post-test disebabkan oleh pemberian informasi yang lengkap terkait pengendalian dan pencegahan hipertensi yang disampaikan pada saat melakukan penyuluhan pada masyarakat Desa Aluh-Aluh Besar RT. 03. Informasi tersebut disajikan dalam berbagai bentuk media informasi seperti booklet, video senam hipertensi, poster, dan powerpoint sehingga masyarakat desa Aluh-Aluh Besar RT.03 tertarik untuk melihat dan membaca informasi tersebut. Selain itu, tim mahasiswa PBL II juga menjelaskan kembali terkait informasi yang terdapat pada media, sehingga masyarakat lebih memahami isi dari media informasi tersebut.

Media informasi melalui booklet merupakan media pendidikan berbentuk buku kecil yang berisi tulisan, gambar ataupun keduanya. Penyajian booklet yang menggunakan banyak gambar dan warna memberikan tampilan yang lebih menarik (Rehusisma, Indriwati and Suarsini, 2017). Pada kegiatan ini, booklet berisikan informasi seputar hipertensi beserta pencegahannya. Berdasarkan penelitian Wijayanti dan Budhi M pada tahun 2018 di Puskesmas Kecamatan 
Pasar Minggu, diketahui bahwa terdapat pengaruh pendidikan kesehatan menggunakan booklet terhadap pemahaman pasien hipertensi (Wijayanti and Mulyadi, 2019). Berikut isi media booklet dapat dilihat pada gambar 1 .

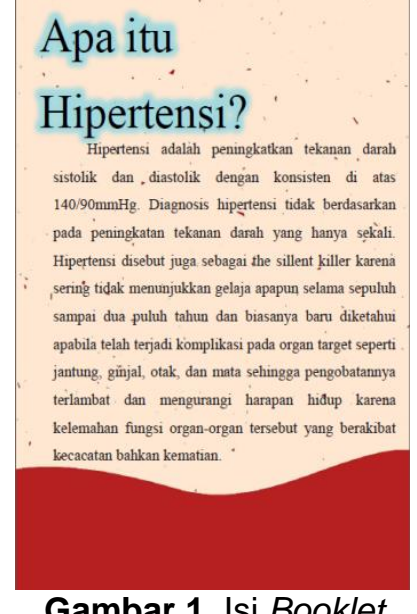

Media yang digunakan selain booklet yaitu media video, informasi melalui video merupakan salah satu media yang dapat digunakan dalam pembelajaran menyimak. Media video ini dapat menambah minat seseorang dalam belajar karena dapat menyimak sekaligus melihat gambar (Yuanta, 2019). Berdasarkan penelitian IImi dan Rolyani pada tahun 2018 di Desa Suradita mengatakan bahwa lansia yang sudah diberikan pendidikan kesehatan dengan metode video mengalami peningkatan pengetahuan hipertensi dari yang tidak tahu menjadi tahu. Pemberian pendidikan kesehatan dengan metode video dapat digunakan sebagai intervensi keperawatan mendidik, juga dapat dikembangkan dalam pendidikan keperawatan guna peningkatan kualitas pelayanan yang komprehensif (Lansia et al., 2018). Berikut isi media video dapat dilihat pada gambar 2 .

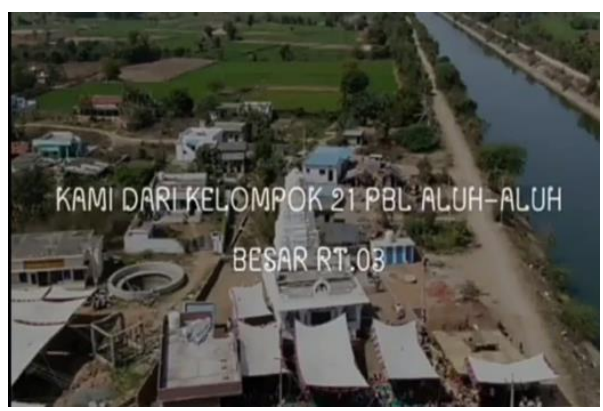

Gambar 2. Isi Video

Media yang digunakan selain video yaitu media poster, informasi melalui poster merupakan gambar yang berisi informasi pada kertas berukuran besar, yang ditempelkan di dinding atau tempat-tempat tertentu agar dapat dilihat oleh banyak orang. Poster bermanfaat untuk memberikan pemahaman tentang suatu informasi kepada banyak orang atau para pembaca mengenai apa yang ingin di sampaikan oleh pembuat poster menggunakan gambar dan kata-kata yang singkat, sederhana dan jelas (Prihadi, 2018). Berdasarkan penelitian Ulya Z dkk pada tahun 2017 di Desa Banteran Kecamatan Sumbang menyatakan bahwa pendidikan kesehatan dengan media poster lebih efektif meningkatkan pengetahuan manajemen hipertensi dibandingkan dengan pemberian pendidikan kesehatan tanpa poster. Beberapa responden saat penelitian mengatakan tertarik untuk membaca poster dikarenakan poster disertai warna dan gambar, sehingga membuat responden penasaran dan membacanya berulang kali. Selain itu, bentuknya yang sederhana dan mudah ditempel dimana saja memudahkan pembaca untuk membaca poster tanpa harus mencarinya terlebih dahulu (Ulya and Iskandar, 2017). Berikut isi media poster dapat dilihat pada gambar 3.

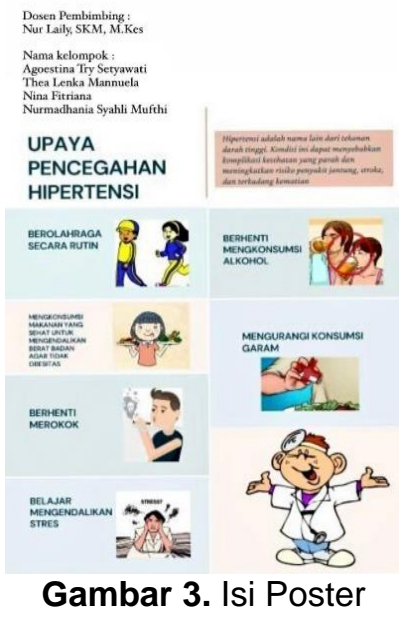

Media yang dibagikan berupa booklet, poster, video, dan powerpoint mengenai penyakit hipertensi di Grup WhatsApp Desa Aluh-Aluh Besar RT.03. Pelaksanaan PBL II memiliki kelemahan dan kelebihan, untuk kelemahan dari kegiatan PBL II yaitu sulitnya mencari kontak warga, sulitnya warga dalam membuka media yang telah diberikan, dan kurangnya respon dari warga pada saat pemberian materi dan tanya jawab. Kemudian, untuk kelebihan dalam pelaksanaan kegiatan PBL II yaitu masyarakat mendapatkan penyuluhan mengenai pengendalian dan pencegahan hipertensi, masyarakat mendapatkan kompensasi berupa pulsa, dan dapat meningkatkan pengetahuan, sikap dan bisa merubah perilaku masyarakat tentang pola hidup sehat serta pencegahan penyakit hipertensi. Namun, tim mahasiswa PBL II mempunyai solusi untuk menanggulangi kendala yang ada pada saat PBL II seperti 
mencari kontak dengan bantuan UP PBL, Ketua RT, Bapak rumah, dan Warga RT. 03, memberikan pesan teks agar warga yang mengalami kesulitan mengakses media tersebut, dapat menerima informasi yang sama, dan pada saat pemberian media tim mahasiswa PBL II memberikan kesempatan pada warga untuk memberikan tanggapan.

\section{SIMPULAN DAN SARAN}

Berdasarkan Kegiatan Pengalaman Belajar Lapangan yang dilakukan pada masyarakat Desa Aluh-Aluh Besar RT. 03 melalui grup WhatsApp, dapat disimpulkan terjadi peningkatan pengetahuan mengenai pengendalian dan pencegahan hipertensi, dengan hasil $p$ value 0,034 yang artinya terdapat perbedaan tingkat pengetahuan pada pengendalian dan pencegahan hipertensi. Sedangkan, untuk sikap didapatkan hasil $p$ value 0,059 yang artinya terdapat perbedaan tingkat sikap pada pengendalian dan pencegahan hipertensi. Melalui kegiatan ini juga terdapat seorang kader terpilih yang membantu masyarakat dalam mencegah penyakit hipertensi dan mengingatkan masyarakat Desa Aluh-Aluh Besar RT. 03 untuk rutin melakukan pemeriksaan tekanan darah ke fasilitas pelayanan kesehatan terdekat.

Harapannya setalah kegiatan ini masyarakat dapat lebih sadar dan peduli akan kesehatan mereka khususnya dalam hal pencegahan dan pengendalian penyakit hipertensi, serta aktif dalam penyuluhan pentingnya melalukan pemeriksaan tekanan darah khususnya bagi penderita hipertensi. Masyarakat juga diharapkan dapat lebih memperhatikan satu sama lain untuk rutin melakukan pengecekan tekanan darah, rutin melakukan aktivitas fisik, serta pergi ke fasilitas pelayanan kesehatan terdekat saat sakit, sehingga nantinya dapat menciptakan derajat kesehatan yang lebih baik.

\section{UCAPAN TERIMAKASIH}

Penulis mengucapkan terima kasih yang sebesar-besarnya kepada seluruh pihak yang mendukung dan berpartisipasi dalam seluruh rangkaian kegiatan Pengalaman Belajar Lapangan mulai dari awal hingga berakhirnya kegiatan, yaitu kepada seluruh Aparat Desa Aluh-Aluh Besar, Masyarakat Desa Aluh-Aluh Besar khususnya RT.03, Puskesmas Aluh-Aluh, dan pihak lainnya yang tidak dapat disebutkan satu persatu.

\section{DAFTAR RUJUKAN}

Aryzki, S. et al. (2018). Evaluasi Rasionalitas Pengobatan Hipertensi Di Puskesmas
Pelambuan Banjar Masin Tahun 2017. Jurnal IImiah Manuntung 4(2):120-128. doi: $10.51352 / j i m . v 4 i 2.191$.

Bety Semara Lakhsmi, A. I. Y. (2021). Hipertensi Masa Kini dalam Perspektif Kesehatan Masyarakat. Sanus Medical Journal 1(2):22-25.

Dede Rina, Nita Fitria, H. (2021). Literature Review Hubungan Antara Tipe Kepribadian Dengan Kejadian Hipertensi. Jurnal Keperawatan Kompregensif. 7(1): 15-19. Available at:http://marefateadyan.nashriyat.ir/no de/150.

Desi Aianti, S. F. S. (2018). Hubungan Tingkat Pengetahuan dengan Sikap REmaja tentang Seksualitas di SMA Negeri 5 Kota Batam tahun 2018 8(3): 67-72.

Hendrawan, A. (2019). Gambaran Tingkat Pengetahuan Tenaga Kerja Pt'X' Tentang Undang-Undang Dan Peraturan Kesehatan Dan Keselamatan Kerja. Jurnal Delima Harapan 6(2): 69-81. doi: 10.31935/delima.v6i2.76.

Lansia, P. et al. (2018). Sesudah diberikan Pendidikan Kesehatan dengan Video 1(II): 137-144.

Oktaviarini, E. et al. (2019). Beberapa Faktor yang Berisiko Terhadap Hipertensi pada Pegawai di Wilayah Perimeter Pelabuhan (Studi Kasus Kontrol di Kantor Kesehatan Pelabuhan Kelas II Semarang). Jurnal Epidemiologi Kesehatan Komunitas 4(1): 35-44. doi: 10.14710/jekk.v4i1.4428.

Prihadi, E. (2018). Pengembangan Keterampilan 4C melalui Metode Poster Comment pada Mata Pelajarann PAI dan Budi Pekerti. Rabbani 1(5): 464-479.

Rehusisma, L. A., Indriwati, S. E. and Suarsini, E. (2017). Pengembangan Media Pembelajaran Booklet Dan Video Sebagai Penguatan Karakter Hidup Bersih Dan Sehat. Jurnal Pendidikan: Teori, Penelitian, dan Pengembangan 2(9): 1238-1243.

Ulya, Z. and Iskandar, A. (2017). Pengaruh Pendidikan Kesehatan Dengan Media Poster Terhadap Pengetahuan Manajemen Hipertensi Pada Penderita Hipertensi. Jurnal Keperawatan Soedirman 12(1): 38-46. doi: 10.20884/1.jks.2017.12.1.715.

Wibowo, D. (2018). Hubungan Tingkat Pengetahuan Dengan Sikap Keluarga Tentang Perawatan Arthritis Rheumatoid Pada Lansia Di Desa Pamalayan Kecamatan Cijeungjing 
Kabupaten Ciamis. Jurnal Kesehatan Bakti Tunas Husada: Jurnal IImu-ilmu Keperawatan, Analis Kesehatan dan Farmasi 17(2): 339-356. doi: 10.36465/jkbth.v17i2.261.

Wijayanti, W. and Mulyadi, B. (2019). Pendidikan Kesehatan Menggunakan Booklet Terhadap Pemahaman Pasien Hipertensi Di Puskesmas. Jurnal IImiah IImu Keperawatan Indonesia 8(01): 372-739. doi: 10.33221/jiiki.v8i01.324.

Yuanta, F. (2019). Pengembangan Media Video Pembelajaran IImu Pengetahuan Sosial pada Siswa Sekolah Dasar. Trapsila: Jurnal Pendidikan Dasar 1(2): 91-100. 